\title{
The Action of Aldosterone and Related Corticosteroids on Sodium Transport across the Toad Bladder *
}

\author{
George A. Porter † and Isidore S. Edelman \\ (From the Cardiovascular Research Institute and the Departments of Medicine and Physiology \\ of the University of California School of Medicine, San Francisco, Calif.)
}

The importance of aldosterone and related adrenal steroids in the regulation of renal conservation of $\mathrm{Na}^{+}$and excretion of $\mathrm{K}^{+}$has been established by extensive studies in man and other mammals (1). The complexity of the mammalian kidney, however, makes it difficult to study the chemical pathways involved in the action of mineralocorticoids on cation transport. The prospects for achieving a solution of this problem should be improved considerably by the development of an in vitro preparation with a relatively simple histological structure that responds reproducibly and predictably to aldosterone. Previous studies on the action of mineralocorticoids on active $\mathrm{Na}^{+}$transport by anuran skin in vivo and in vitro made it likely that such a preparation could be developed (2-6). Significant progress in the development of an in vitro system suitable for an analysis of the mechanism of action of aldosterone was made by Crabbé (7-9), who showed that the rate of endogenous secretion of $d$-aldosterone in Bufo marimus varies with the salinity of the environment and that aldosterone stimulates active transport of $\mathrm{Na}^{+}$across the isolated urinary bladder and ventral skin of anurans.

Our objectives were 1) to improve the sensitivity and reproducibility of the response of the toad bladder system to aldosterone, 2) to obtain information on the dependance of the action of

* Submitted for publication October 4, 1963; accepted November 29, 1963.

Financial support was provided by the U. S. Public Health Service, National Heart Institute (grant no. HEO-6285), the American Heart Association, and the San Francisco Heart Association. Preliminary reports of these data were presented at the Annual Meeting of the Western Society for Clinical Research, Carmel, Calif., January 1963, and at the Annual Meeting of the American Society for Clinical Investigation, Atlantic City, N. J., April 1963.

$\dagger$ Work done during the tenure of a special fellowship of the U. S. Public Health Service. aldosterone on an adequate supply of substrate, and 3) to define the structure-activity relationships of natural and synthetic steroids.

\section{Methods}

All of our studies were carried out on the urinary bladder of Bufo marinus at room temperature $\left(21\right.$ to $\left.23^{\circ} \mathrm{C}\right)$. The toads were kept on wet earth without food for 1 to 4 weeks before use. The hemibladders were removed after double pithing the toad and then rinsed in standard frog-Ringer's solution $\left(\mathrm{Na}^{+}=114 \mathrm{mEq}\right.$ per $\mathrm{L}, \mathrm{K}^{+}=$ $3.5 \mathrm{mEq}$ per $\mathrm{L}, \mathrm{Ca}^{2+}=5.4 \mathrm{mEq}$ per $\mathrm{L}, \mathrm{Cl}^{-}=120.4 \mathrm{mEq}$ per $\mathrm{L}, \mathrm{HCO}_{3}^{-}=2.5 \mathrm{mEq}$ per $\mathrm{L}$, osmolality $=0.228$, and $\mathrm{pH}$ in air =8.4). In the first 65 experiments, paired hemibladders were mounted without inducing contraction; in the 68 experiments on structure-activity relationships, the rinsing solution contained $2 \times 10^{-5} \mathrm{M}$ methacholine chloride to induce contraction of the hemibladders at the time of mounting in the chambers. Pretreatment with methacholine increased the number of hemibladders that survived the period of preincubation with a transepithelial potential difference of $5 \mathrm{mv}$ or greater. The magnitude of the response of the shortcircuit current (scc) to either glucose or aldosterone was not altered by this maneuver. The reproducibility of the response to aldosterone, however, was improved to some extent by the use of methacholine. Each hemibladder was mounted as a diaphragm between glass chambers similar in principle to those of Ussing and Zerahn (10). The cross-sectional area of the chamber orifice was $2.54 \mathrm{~cm}^{2}$. To fix the geometrical relation between the agar- $\mathrm{KCl}$ bridges and a hemibladder, both orifices were covered with 30-denier mesh nylon hose kept taut and secured in place with rubber bands; the hemibladders were sandwiched between two discs of nylon hose. The residual methacholine was removed by washing with $40 \mathrm{ml}$ of frog-Ringer's solution $(20 \mathrm{ml}$ per chamber) for 10 to 15 minutes. After these solutions were replaced with fresh frog-Ringer's solution, the scc was measured continuously by the method of Ussing and Zerahn (10) except for brief interruptions of approximately 20 seconds for the measurement of the transepithelial electric potential difference (pd). The voltage clamp was not applied during overnight incubation. Only hemibladders generating a pd of $5 \mathrm{mv}$ or greater were accepted for study. If either member of 
the pair failed to sustain a pd of this magnitude, the pair was discarded.

The solutions added to the standard media did not produce detectable changes in the osmolality or $\mathrm{pH}$ of the standard media. At the times specified in Results $0.5 \mathrm{ml}$ of a freshly prepared solution of $0.23 \mathrm{M}$ glucose was added to each half chamber giving a final concentration of $5.5 \times 10^{-3}$ moles per L. In one set of experiments the medium bathing the mucosal surface was modified to contain a concentration of $\mathrm{Na}^{+}$of $22 \mathrm{mEq}$ per $\mathrm{L}$ (i.e., $\frac{1}{5}$ the concentration of the serosal medium) by substituting the appropriate amount of choline $\mathrm{Cl}$ for $\mathrm{NaCl}$ in frog-Ringer's solution.

The unidirectional flux of $\mathrm{Na}^{+}$was measured in paired experiments: we added $50 \mu \mathrm{c}$ of $\mathrm{Na}^{22}$ to the serosal solution of one hemibladder and the same amount of $\mathrm{Na}^{22}$ to the mucosal solution of the other and determined the quantity of isotope in the contralateral solution at hourly intervals. All samples were obtained in duplicate and assayed in a $\mathrm{NaI}$, thallium-activated, welltype, crystal gamma-ray spectrometer. ${ }^{1}$

The final concentration of all steroids was $7 \times 10^{-7} \mathrm{M}$. In the studies on the relationship between steroidstructure and activity, one hemibladder received $d$-aldosterone, ${ }^{2}$ and the other received one of the following: $9 \alpha$-fluorocortisol, ${ }^{3}$. corticosterone, ${ }^{2}$ desoxycorticosterone acetate (DOCA), ${ }^{2}$ cortisol, 4 prednisolone, ${ }^{3} 2-\mathrm{CH}_{3}-9 \alpha-$ fluorocortisol, 4 2- $\mathrm{CH}_{3}$ cortisol, ${ }^{4}$ or progesterone. ${ }^{5}$ The diluent (20 to $95 \%$ ethanol in water) was always the same for aldosterone and the steroid being compared. Analysis of the results showed that the ethanol content of the diluent did not affect the response of the scc to aldosterone.

\section{Results}

Effects of preincubation and of substrate on the response to aldosterone. Two physiological variables influenced responsiveness to aldosterone: $a$ ) the duration of preincubation in steroid-free media and $b$ ) the presence of exogenous glucose in the media. Since adrenalectomy accentuates the response to corticosteroids $(11,12)$, we studied the first variable on the assumption that the action of exogenous aldosterone on the transport system would be more evident when endogenous aldosterone had been depleted. The effect of glucose on the action of aldosterone was studied because Maffly and Edelman (13) found that the

\footnotetext{
1 Packard Instrument Corp., La Grange, Ill. 2 California Biochemical Research Corp., Los Angeles, Calif.

${ }^{3}$ Merck Sharp \& Dohme, Inc., Philadelphia, Pa.

4 Upjohn Co., Kalamazoo, Mich.

5 Invernex Corp., San Francisco, Calif.
}

scc was dependent on exogenous substrate after 5 hours of incubation in vitro.

We used four experimental protocols to investigate these two physiological variables. In the first set (8 experiments) paired hemibladders were preincubated in frog-Ringer's solution for 4 hours, and $d$-aldosterone was then added to the serosal solution of one hemibladder and diluent to the serosal solution of the other hemibladder. For the second set (9 experiments) paired hemibladders were preincubated for 2 hours in frogRinger's solution, and glucose was then added to the serosal and mucosal media of both hemibladders. After incubating the hemibladders for an additional 2 hours in glucose-fortified media, $d$-aldosterone was added to the serosal solution of one hemibladder and diluent to the other. The protocol for the third set (7 experiments) was as follows: paired hemibladders were preincubated in aerated frog-Ringer's solution for about 15 hours, all solutions were then exchanged with fresh frog-Ringer's solution, and $d$-aldosterone was then added to the serosal solution of one hemibladder and diluent to the serosal solution of the other hemibladder. In the fourth set (8 experiments) paired hemibladders were preincubated in aerated frog-Ringer's solution for about 15 hours, all solutions were then exchanged for fresh frog-Ringer's solution, and glucose was then added to the serosal and mucosal media of both hemibladders. ${ }^{6}$ The hemibladders were incubated for an additional 2 hours in glucosefortified media, and then $d$-aldosterone was added to the serosal solution of one hemibladder and diluent to the serosal solution of the other.

A quantitative index of the response to aldosterone was obtained by dividing the scc or pd observed at time " $t$ " after the introduction of aldosterone by the respective values recorded $\frac{1}{2}$ hour before the addition of aldosterone (time zero was taken as the time of addition of aldosterone). The prealdosterone base-line values are denoted by $\mathrm{scc}_{-\frac{1}{2}}$ and $\mathrm{pd}_{-\frac{1}{1}}$, and the postaldosterone values by $\operatorname{scc}_{t}$ and $\operatorname{pd}_{t}$.

The results obtained in the first set of experiments are shown in Figure 1. The scc of the steroid-treated group declined at the same rate as that

\footnotetext{
${ }^{6}$ After 15 hours of preincubation in frog-Ringer's solution, the $\mathrm{pH}$ of the media averaged 8.35 (in air) compared with a value of 8.40 (in air) of fresh media.
} 

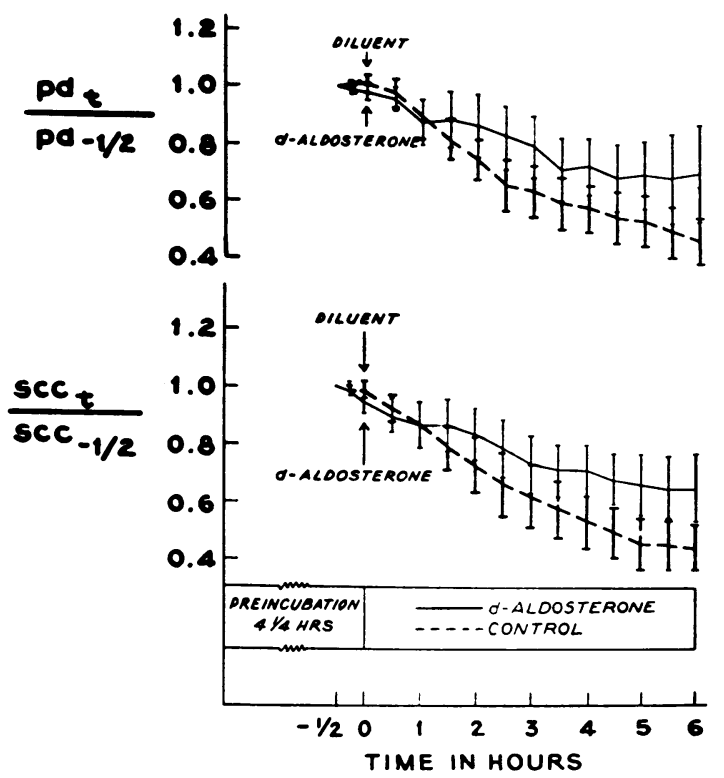

Fig. 1. RESPONSE OF SHORT-CIRCUIT CURRENT (SCC) AND POTENTIAL DIFFERENCE (PD) TO ALDOSTERONE (SEROSAL MEDIUM) AFTER PREINCUBATING HEMIBLADDER 4! HOURS IN SUBSTRATE-FREE MEDIA. The method of computation of the pd and scc ratios is described in the text. Time zero was set at the time of addition of aldosterone to the serosal solution of one of the hemibladders and of the diluent to the serosal solution of the other hemibladder. The solid line connects the mean values recorded for the hemibladders that received aldosterone and the broken line the mean values of the controls. One standard error of the mean is indicated by the vertical bars. The experimental sequence is given immediately above the abscissa.

of the control group for approximately 1 hour; thereafter the rate of decline was distinctly slower in the group exposed to aldosterone. The same pattern was seen in the response of the pd to aldosterone.

In the second set of experiments (i.e., 2 hours of preincubation in frog-Ringer's solution, followed by 2 hours of preincubation in glucosefortified media) the scc and pd tended to rise progressively but, on the average, the rise was less in the aldosterone-treated group, indicating that other maneuvers were needed to obtain a satisfactory system.

As shown in Figure 2, extending the period of preincubation to 15 hours accentuated the response to aldosterone; the control hemibladders showed a monotonic fall in scc and pd, whereas the steroid-treated group maintained fairly steady values after a latent period of about 90 minutes.
In contrast to the results obtained in the first three sets of experiments, the combination of 15 hours of preincubation plus 2 hours in glucosefortified media gave a highly responsive and reproducible system as shown in Figure 3. The scc and pd rose progressively and linearly in the aldosterone-treated group for $4 \frac{1}{2}$ hours after a latent period of 90 minutes. At 6 hours the scc ratio averaged $2.10 \pm 0.31$, and the pd ratio averaged $1.22 \pm 0.15$ in the steroid-treated group, whereas the control ratios were $0.72 \pm 0.13$ for scc and $0.53 \pm 0.09$ for pd. These results indicate that prolonged preincubation sensitizes the toad bladder system to the action of aldosterone on $\mathrm{Na}^{+}$transport, provided that an adequate supply of substrate is available.

The effect of aldosterone on $\mathrm{Na}^{+}$transport against a gradient. In vivo aldosterone mediates the conservation of $\mathrm{Na}^{+}$, despite the presence of opposing electrical and chemical gradients, at the expense of energy derived from metabolic transformations. If convection is neglected (the osmolality of the serosal and mucosal solutions were identical so that no external osmotic gradient was present), Heinz and Patlak (14) proposed
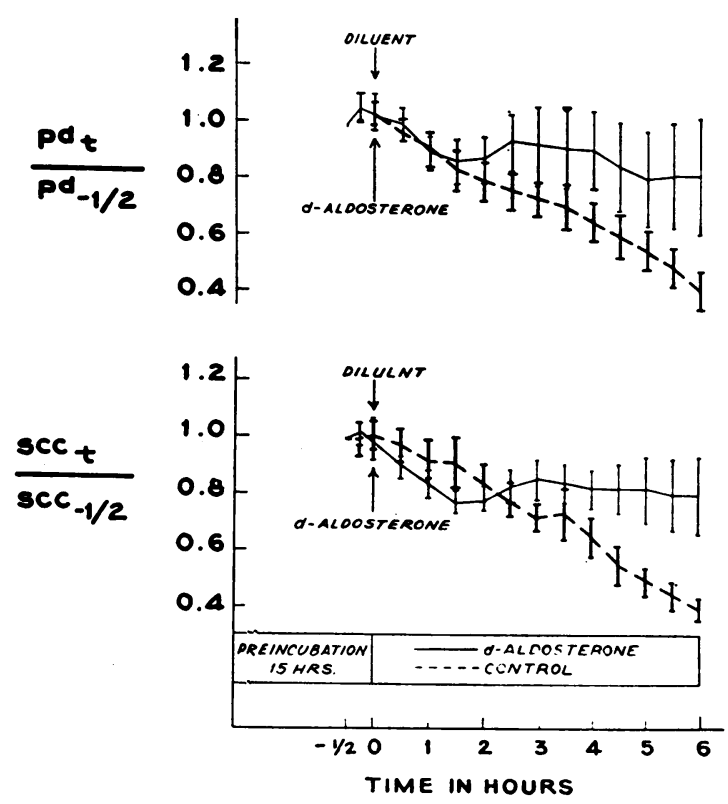

Fig. 2. Response of SCC AND PD to aldosterone (SERoSAL MEDIUM) AFTER PREINCUBATING HEMIBLADDERS FOR 15 HOURS IN SUBSTRATE-FREE MEDIA. The method of computing the pd and scc ratios is described in the text. The conventions used in the construction of this figure are the same as in Figure 1. 


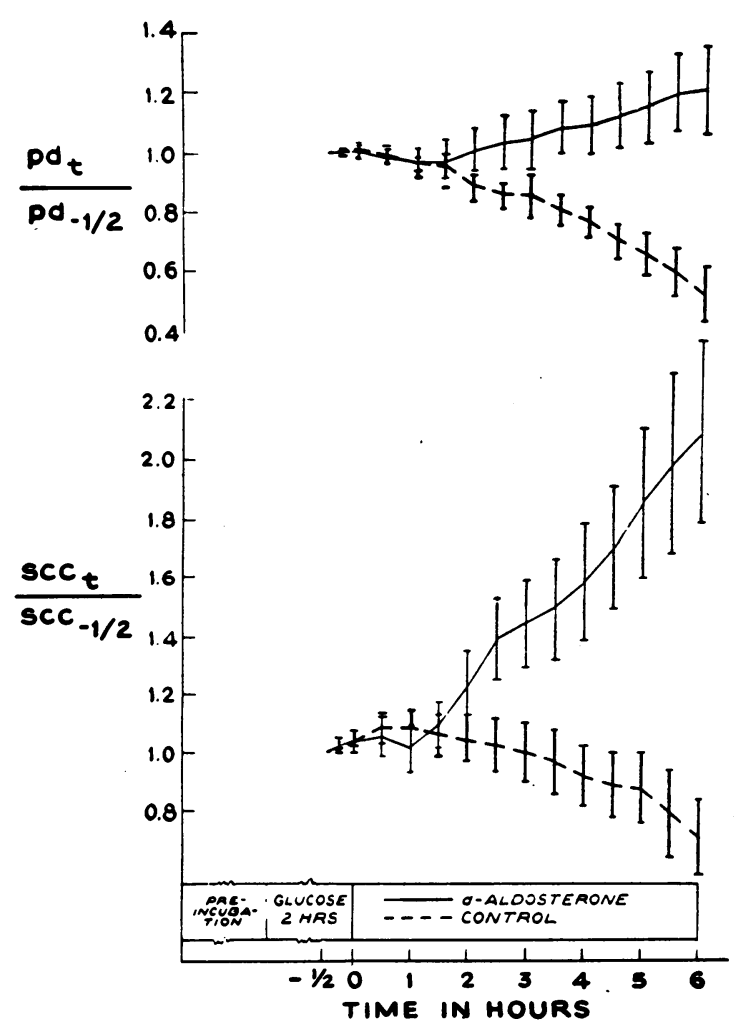

Fig. 3. RESPONSE OF SCC AND PD to ALDOSTERONE (SERoSAL MEDIUM) AFTER PREINCUBATING HEMIBLADDERS 14? HOURS IN SUBSTRATE-FREE MEDIA FOLLOWED BY 2 HOURS of PREINCUBATION IN GLUCOSE-ForTified MEdia. The method of computing the pd and scc ratios is described in the text. The conventions used in the construction of this figure are the same as in Figure 1.

that the work per mole of $\mathrm{Na}^{+}$transported $(W)$ from the mucosal to the serosal solution is given by

$$
W \geqq R T \ln \frac{C_{s}}{C_{m}}+F \Delta E+R T \ln \frac{J_{m s}}{J_{s m}},
$$

where $R$ is the gas constant, $T$ the absolute temperature, $C_{8}$ the concentration of $\mathrm{Na}^{+}$in the serosal solution, $C_{m}$ the concentration of $\mathrm{Na}^{+}$in the mucosal solution, $F$ the Faraday constant, $\Delta E$ the difference in electrical potential, $J_{m s}$ the unidirectional flux of $\mathrm{Na}^{+}$. from the mucosa to the serosa, and $J_{s m}$ the unidirectional flux from serosa to mucosa. With the pd clamped at zero, Equation 1 reduces to:

$$
W \geqq R T\left[\ln \frac{C_{s}}{C_{m}}+\ln \frac{J_{m s}}{J_{s m}}\right] .
$$

In 12 paired experiments (to be described as the sixth set of experiments) flux ratios $\left(J_{m s} / J_{s m}\right)$ were determined with $\mathrm{Na}^{22}$ and averaged $2.9 \pm$ 0.4 in the steroid-free solutions and $4.4 \pm 0.6$ in the solutions containing aldosterone $\left(7 \times 10^{-7} \mathrm{M}\right)$. The $>$ sign denotes the possible existence of nonmeasurable irreversible losses of energy in the process of regenerating elements of the $\mathrm{Na}^{+}$transport system. If we assume that the nonmeasurable terms are approximately constant, the residual work output per mole net flux of $\mathrm{Na}^{+}$will be more than doubled if the ratio $C_{s} / C_{m}$ is set at $5: 1$. In our fifth set of experiments the effect of aldosterone on the scc was measured at a $\mathrm{Na}^{+}$ concentration of $22 \mathrm{mEq}$ per $\mathrm{L}$ in the mucosal

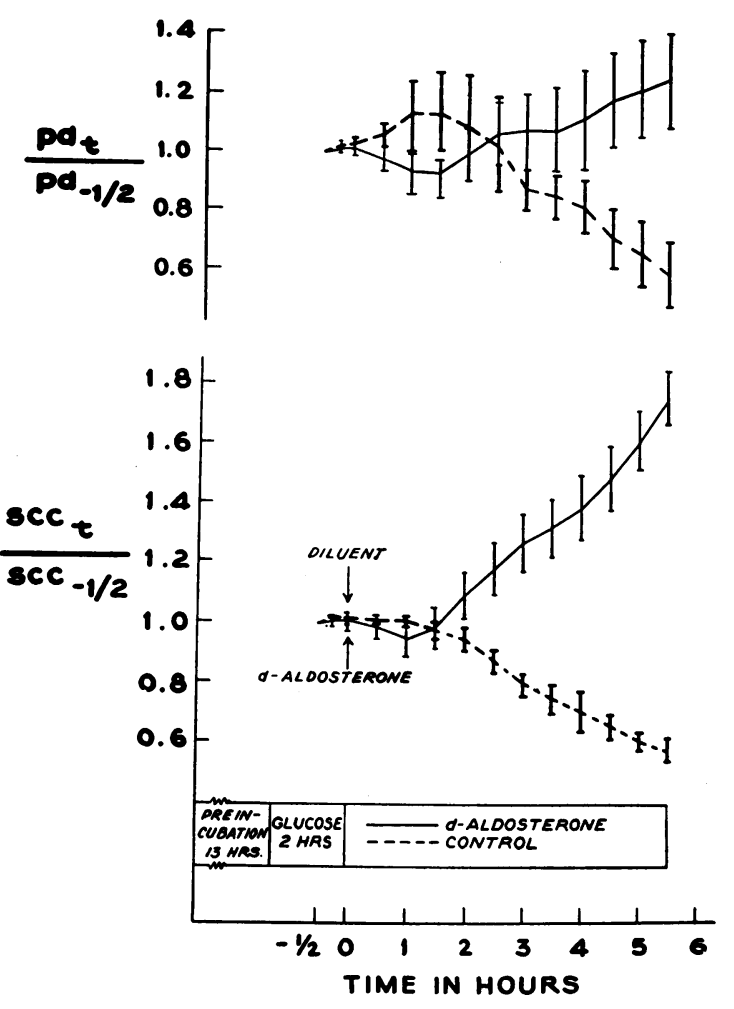

Fig. 4. Response of the sCC ANd PD to aldosterone (SEROSAL MEDIUM) AFTER HEMIBLADDERS HAD BEEN PREINCUBATED IN SUBSTRATE-FREE MEDIA FOR 13 HOURS, FOLLOWED BY 2 HOURS OF PREINCUBATION IN GLUCOSE-FORTIFIED MEDIA. The mucosal solution contained $\mathrm{Na}^{+}$at a concentration of $22 \mathrm{mEq}$ per $\mathrm{L}$ and choline $^{+}$at a concentration of $92 \mathrm{mEq}$ per L. Standard frog-Ringer's solution $\left(\mathrm{Na}^{+}=114 \mathrm{mEq}\right.$ per $\left.\mathrm{L}\right)$ was used on the serosal side. The method of computing the pd and scc ratios is described in the text. The conventions used in the construction of this figure are the same as in Figure 1. 
solution. Choline was substituted for $\mathrm{Na}^{+}$in equimolar quantities in the mucosal solutions to maintain isosmotic conditions. Frazier, Dempsey, and Leaf (15) found a good correlation between scc and the unidirectional (mucosal to serosal) flux of $\mathrm{Na}^{22}$ at a concentration of $20 \mathrm{mEq}$ per $\mathrm{L}$ of $\mathrm{Na}^{+}$in the mucosal solution and no $\mathrm{Na}^{+}$ in the serosal solution. In our experiments the concentration gradient favors serosal to mucosal diffusion of $\mathrm{Na}^{+}$. Under these circumstances the scc may underestimate the magnitude of transport in the active direction. In subsequent experiments we found no effect of aldosterone on the passive serosal to mucosal flux of $\mathrm{Na}^{+}$, suggesting that the changes noted in the presence of a 5:1 gradient can be assigned to effects on transport in the active direction. The results shown in Figure 4 indicate that in glucose-fortified media aldosterone provokes a rise in scc against a fivefold concentration gradient of $\mathrm{Na}^{+}$comparable to the rise seen in isomolar solutions ( $c f$. Figure 3 and Table II). The combined action of steroid and substrate, therefore, is to increase the output of transport work.

Effect of aldosterone on unidirectional fux of $\mathrm{Na}^{+}$. Crabbe (8) found that the rise in scc induced by aldosterone was matched by an equal increase in net $\mathrm{Na}^{+}$flux. This increase may result either from an increase in the mucosal to serosal flux (i.e., the active path) or from a decrease in the serosal to mucosal flux (i.e., the passive path). In the latter case, the mechanism of action might involve the passive permeability properties of the serosal surface of the epithelial cells; in the former it might involve either the passive permeability of the cell membrane of the mucosal surface or a direct action on the $\mathrm{Na}^{+}$pump. In our sixth set of experiments unidirectional fluxes were measured in paired hemibladders before and after the introduction of aldosterone. Pairs of hemibladders were preincubated for 15 hours in steroidfree media, the media were then exchanged for glucose-fortified media, and 2 hours later aldosterone $\left(7 \times 10^{-7} \mathrm{M}\right)$ was added to the serosal media. Figure 5 shows that within the limits of experimental error there was a $1: 1$ correspondence between the increase in the scc (expressed in microequivalents per hour) and the increase in the unidirectional flux of $\mathrm{Na}^{+}$from mucosa to serosa induced by aldosterone. The absolute in-

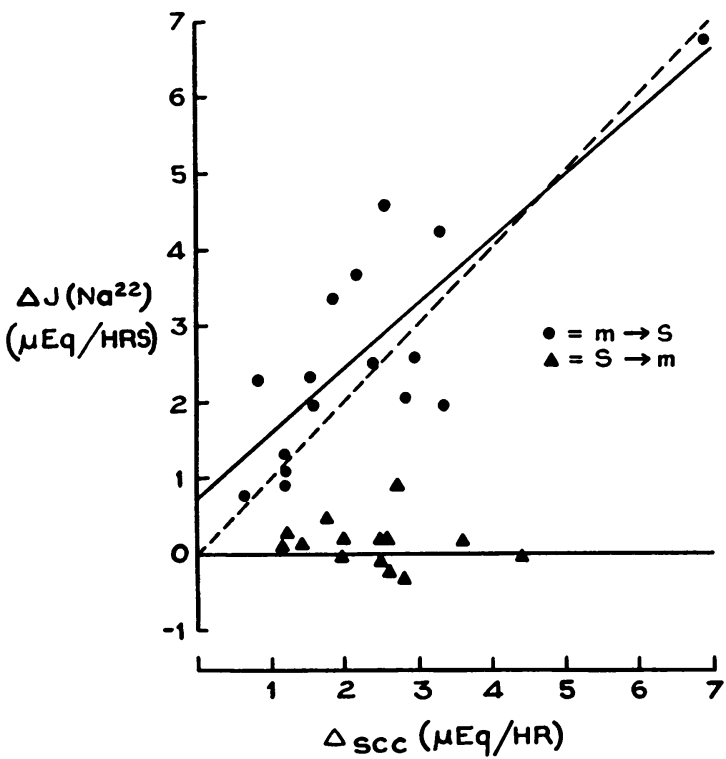

Fig. 5. The Relationship BETWEen the Change in THE UNIDIRECTIONAL FLUX OF $\mathrm{NA}^{+}$AND THE SCC 6 HOURS AFTER THE ADDITION OF ALDOSTERONE TO THE SEROSAL MEDIUM. The change in unidirectional flux (measured with $\mathrm{Na}^{22}$ ) is plotted on the ordinate. The circles represent the quantity $\left[J_{m s}\left(t_{2}\right)-J_{m},\left(t_{1}\right)\right]$, where $J_{m s}\left(t_{2}\right)$ is the flux of $\mathrm{Na}^{+}$from the mucosal to the serosal solution during the fifth to the sixth hour after the addition of aldosterone and $J_{m},\left(t_{1}\right)$ the corresponding flux for the interval from $\frac{1}{2}$ hour before to $\frac{1}{2}$ hour after the addition of aldosterone. The triangles represent the quantity [ $J_{s m}\left(t_{2}\right)-J_{s m}\left(t_{1}\right)$ ], where $J_{s m}\left(t_{2}\right)$ is the serosal to mucosal flux of $\mathrm{Na}^{+}$during the fifth to sixth hours after the addition of aldosterone and $J_{\bullet m}\left(t_{1}\right)$ the corresponding flux for the interval from $\frac{1}{2}$ hour before to $\frac{1}{2}$ hour after the addition of aldosterone. The change in the scc $\left[\operatorname{scc}\left(t_{2}\right)-\operatorname{scc}\left(t_{1}\right)\right.$ ] expressed in microequivalents per hour is plotted on the abscissa, where $\operatorname{scc}\left(t_{2}\right)$ is the average scc for the interval from the fifth to the sixth hour after the addition of aldosterone and $\operatorname{scc}\left(t_{1}\right)$ the average scc for the interval from $\frac{1}{2}$ hour before to $\frac{1}{2}$ hour after the addition of aldosterone. The broken line is the theoretical line for a $1: 1$ correlation. The solid line is a least squares fit of the simultaneously measured values for $\left[J_{m s}\left(t_{2}\right)-J_{m s}\left(t_{1}\right)\right]$ and $\left[\operatorname{scc}\left(t_{2}\right)-\right.$ $\left.\operatorname{scc}\left(t_{1}\right)\right]$.

crease in the unidirectional flux of $\mathrm{Na}^{+}$from mucosa to serosa after 5 to 6 hours of exposure to aldosterone ranged from 0.8 to $6.5 \mu \mathrm{Eq}$ per hour per $2.54 \mathrm{~cm}^{2}$. The back-diffusion of $\mathrm{Na}^{+}$from the serosal to the mucosal solutions is virtually unchanged (i.e., $\Delta J_{s m} \cong 0.0$ ), suggesting that aldosterone does not act by decreasing the passive permeability of the serosal face of the epithelial cell membranes. 


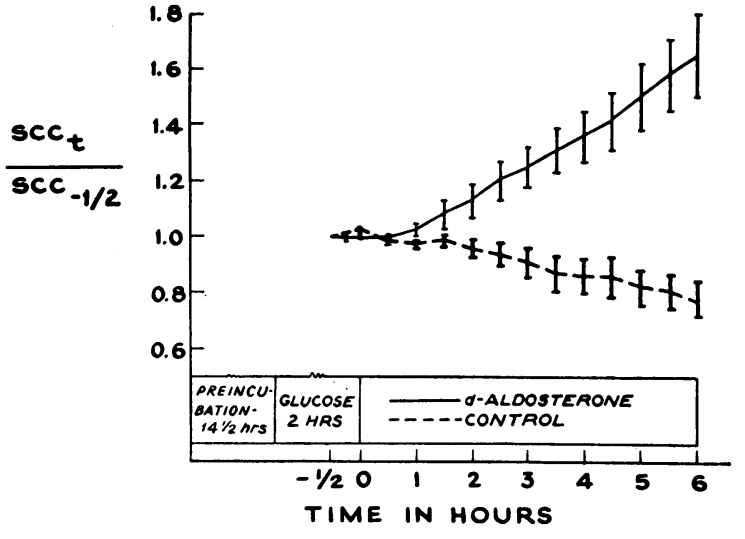

Fig. 6. RESPONSE OF THE SCC TO THE ADDITION OF ALDOSTERONE TO THE MUCOSAL MEDIUM AFTER $14 \frac{1}{2}$ HOURS OF PREINCUBATION IN SUBSTRATE-FREE MEDIA FOLLOWED BY 2 HOURS OF PREINCUBATION IN GLUCOSE-FORTIFIED MEDIA. The method of computing the scc ratio is described in the text. The conventions used in the construction of this figure are the same as in Figure 1.

Action of aldosterone from the mucosal side. Crabbé (9) did not find an effect of aldosterone on scc when the steroid was added to the mucosal solution. We restudied this question using the following protocol for our seventh set of experiments. Paired hemibladders were preincubated for about 14 hours in frog-Ringer's solu- tion, and then glucose was added to the media. After the hemibladders had been an additional 2 hours in glucose-fortified media, $d$-aldosterone was added to the mucosal solution of one hemibladder and diluent to the other. The results shown in Figure 6 indicate that the addition of aldosterone to the mucosal solution induces an increase in active $\mathrm{Na}^{+}$transport similar in magnitude to the increase induced by addition to the serosal solution ( $c f$. Figures 3 and 6). Six hours after the addition of aldosterone to the mucosal solution, the ratio $\mathrm{scc}_{t} / \mathrm{scc}_{-\frac{1}{2}}$ averaged $1.56 \pm 0.15$ in the steroid-treated group and $0.78 \pm 0.06$ in the control group. The latent period averaged about 1 hour after the addition to the mucosal side compared with an average figure of about 1.5 hours after addition to the serosal side.

Structure-activity relationships. Definition of the relationships between steroidal structure and activity on $\mathrm{Na}^{+}$transport may provide useful clues to the mechanism of mineralocorticoid action. The plan of the eighth set of experiments was as follows: Paired hemibladders were preincubated in frog-Ringer's solution for about 14 hours, and the bathing media were then replaced with glucose-fortified Ringer's solution. Two hours after the addition of glucose, $d$-aldosterone

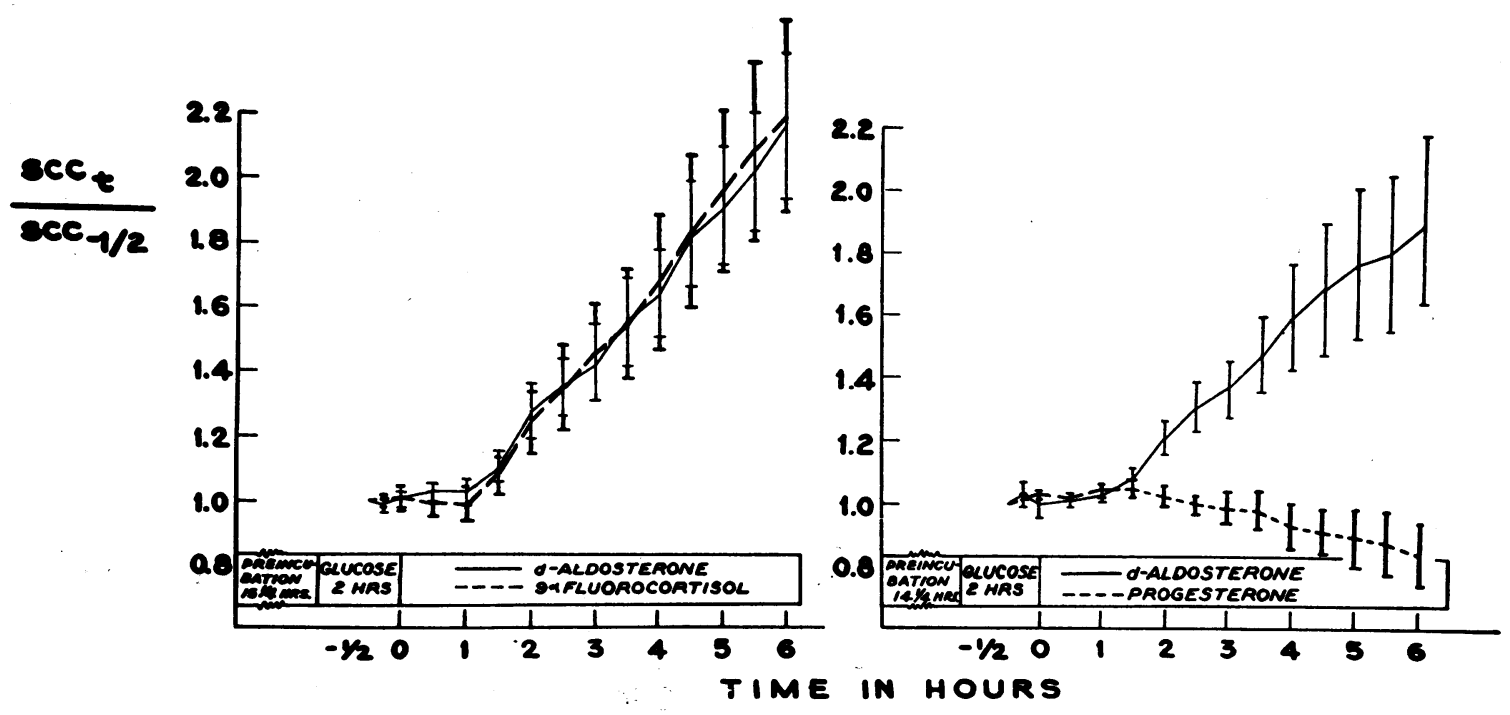

Fig. 7. Structure-Activity Relationships For ALDOSTERone vs. $9 \alpha$-Fluorocortisol ANd For aldosterone vs. PRogesterone. The scc ratio computed as given in the text is plotted on the ordinate and time in hours on the abscissa. The solid line connects the values obtained in the aldosterone-treated hemibladders. The dotted line connects the values obtained in the $9 \alpha$-fluorocortisol treated hemibladders in the left-hand panel and those obtained in the progesterone treated hemibladders in the right-hand panel. The remaining conventions used in the construction of this figure are the same as in Figure 1. 
TABLE I

A comparison of the electrophysiologic effects of various steroids at $7 \times 10^{-7}$ moles per $L^{*}$

\begin{tabular}{|c|c|c|c|c|c|c|c|c|c|}
\hline \multirow[b]{3}{*}{ Steroid } & \multirow[b]{3}{*}{$x$} & \multicolumn{4}{|c|}{ Relative activity (scc) } & \multicolumn{4}{|c|}{ Relative activity (pd) } \\
\hline & & \multicolumn{2}{|c|}{$3 \mathrm{hrs}$} & \multicolumn{2}{|c|}{$6 \mathrm{hrs}$} & \multicolumn{2}{|c|}{$3 \mathrm{hrs}$} & \multicolumn{2}{|c|}{$6 \mathrm{hrs}$} \\
\hline & & $\mathrm{RT}$ & $\mathrm{p} \ddagger$ & $\mathrm{RT}$ & $\mathrm{p} \ddagger$ & $\mathrm{R} \dagger$ & $\mathrm{p} \ddagger$ & $\mathbf{R t}$ & $\mathrm{p} \ddagger$ \\
\hline Aldosterone & & 1.00 & & 1.00 & & 1.00 & & 1.00 & \\
\hline $9 \alpha$-fluorocortisol & 7 & 1.01 & $>0.9$ & 1.02 & $>0.9$ & 1.04 & $>0.9$ & 0.97 & $>0.8$ \\
\hline DOCA & 10 & 0.85 & $>0.05$ & 0.93 & $>0.2$ & 0.89 & $>0.2$ & 0.94 & $>0.6$ \\
\hline Cortisol & 8 & 0.94 & $>0.05$ & 0.86 & $>0.05$ & 0.92 & $>0.05$ & 0.82 & 0.05 \\
\hline Corticosterone & 8 & 0.86 & $<0.025$ & 0.86 & $<0.05$ & 0.86 & $<0.05$ & 0.84 & $>0.10$ \\
\hline Prednisolone & 8 & 0.92 & $>0.2$ & 0.83 & $>0.5$ & 0.98 & $>0.8$ & 0.91 & $>0.5$ \\
\hline $\begin{array}{l}2 \cdot \mathrm{CH}_{3-9} \alpha-\text { fluoro- } \\
\text { cortisol }\end{array}$ & 7 & 0.81 & 0.025 & 0.68 & 0.05 & 0.92 & 0.9 & 0.71 & 0.2 \\
\hline $2 \cdot \mathrm{CH}_{3}$-cortisol & 7 & 0.77 & $<0.005$ & 0.49 & 0.010 & 0.77 & $>0.05$ & 0.54 & $<0.025$ \\
\hline Progesterone & 8 & 0.72 & $<0.001$ & 0.44 & $<0.01$ & 0.72 & $<0.01$ & 0.42 & $<0.01$ \\
\hline None & 8 & 0.70 & $<0.001$ & 0.36 & $<0.001$ & 0.82 & $>0.01$ & 0.43 & 0.001 \\
\hline
\end{tabular}

* Scc $=$ short-circuit current $; \mathrm{pd}=$ potential difference; $\mathrm{N}=$ number of paired experiments (in the eighth set); DOCA = desoxycorticosterone acetate.

$\dagger$ The ratio of activity was computed as given in the text. The mean value was computed for each species at 3 hours and at 6 hours after addition of the steroid.

$\ddagger$ The $\mathrm{p}$ value was calculated from the $t$ test for paired observations.

was added to the serosal medium of one of the hemibladders and the steroid under study to the serosal medium of the other. Seventy-one paired studies were carried out. Figure 7 shows the results obtained in two groups of experiments, $d$-aldosterone vs. $9 \boldsymbol{\alpha}$-fluorocortisol and $d$-aldosterone vs. progesterone. $9 \alpha$-fluorocortisol is fully as active as aldosterone, in contrast to proges-

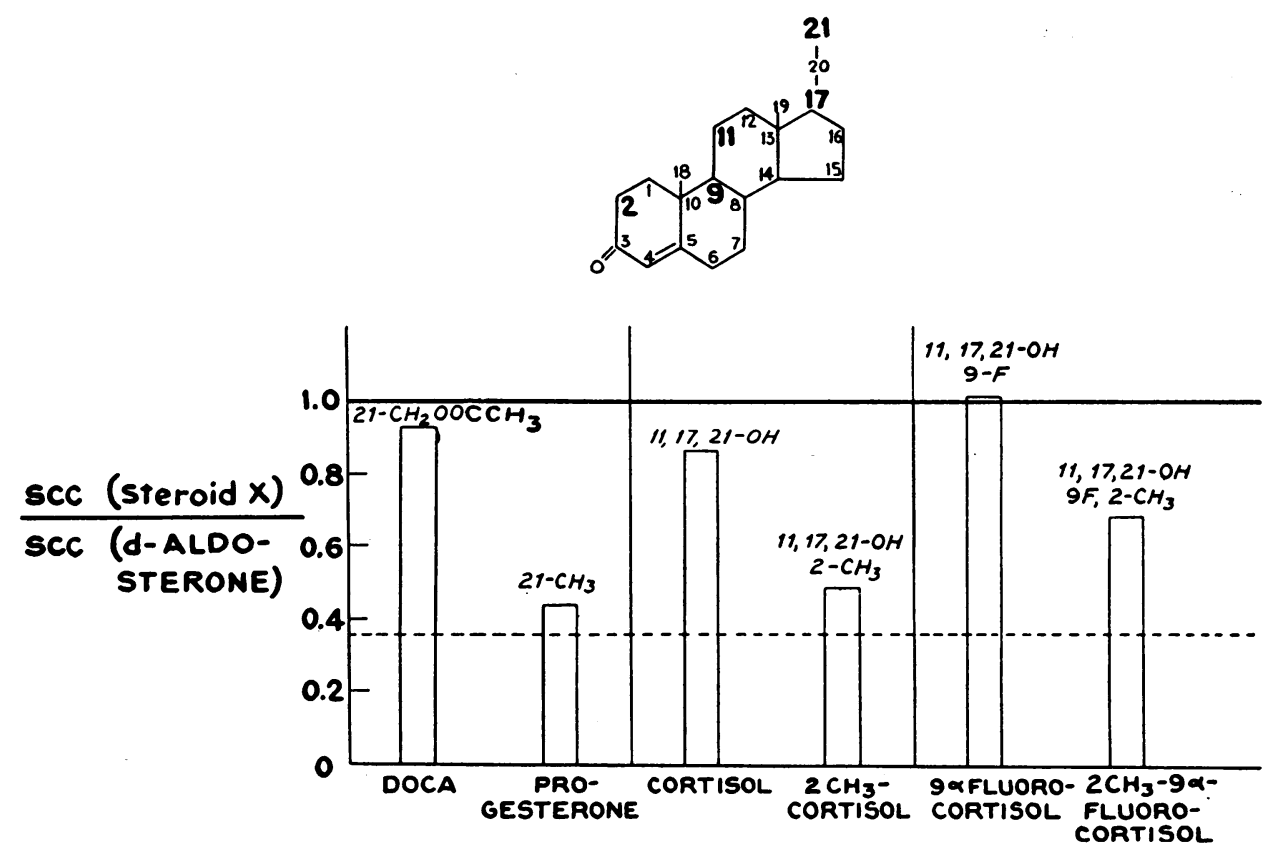

Fig. 8. Structure-Activity Relationships in the action of Mineralocorticoids on $\mathrm{NA}^{+}$ TRANSPORT. The quotient of the scc ratios for each of the steroids and the scc ratio of aldosterone at the end of 6 hours after the addition of the steroids to the serosal media is given on the ordinate. The method of computing the scc quotients is given in the text. The values shown in this figure were taken from Table I. The basic ring structure of the steroid molecule is shown as a means of illustrating the differences in structure. The broken line indicates no steroid response. 
terone, which has little or no activity. A quantitative index of the relative activity was computed by dividing the $\operatorname{scc}$ ratio (i.e., $\operatorname{scc}_{\mathrm{t}} / \mathrm{scc}_{-\frac{1}{2}}$ ) for aldosterone by the scc ratio of the test steroid at 3 hours and at 6 hours after addition. The activity of aldosterone was set at a quotient of 1.0. The same computation was used to obtain a quotient expressing the effect of the steroids on the pd relative to the effect of aldosterone. The activities of $9 \alpha$-fluorocortisol, DOCA, cortisol, and prednisolone were not significantly different statistically from those of aldosterone (Table I). At the end of 6 hours, however, the rise in $\mathrm{Na}^{+}$ transport above the base line tended to be somewhat less with cortisol and prednisolone than with aldosterone. These results indicate that unsaturation of the 1,2 bond has little effect on steroidal activity on $\mathrm{Na}^{+}$transport (compare cortisol to prednisolone). Although the average scc and pd ratios for corticosterone were similar to those of cortisol, the scc ratio for corticosterone was significant at the $5 \%$ level at the end of 3 and 6 hours. 2- $\mathrm{CH}_{3}-9 \alpha$-fluorocortisol and $2-\mathrm{CH}_{3}$-cortisol had a lesser effect on scc than aldosterone, and progesterone had little or no activity (compare progesterone and no steroid).

The pertinent features of some of the relationships between structure and activity are illustrated in Figure 8. Since DOCA is fully active, whereas progesterone has virtually no activity, the acetate or a similar group in the C-21 position is required for $\mathrm{Na}^{+}$transport activity. The substitution of a hydrophobic function at the C-2 position suppresses but does not abolish activity.

The results have been given in relative units to indicate the pattern of the response to steroids without regard to variations in the base line values before the addition of aldosterone. To establish that the absolute response to aldosterone and related mineralocorticoids was also highly significant, the base-line scc values and the values obtained after 360 minutes of exposure to steroid are given in Table II. The smallest average absolute increase after 6 hours of aldosterone was $23 \mu \mathrm{a}$ per $2.54 \mathrm{~cm}^{2}$ in the fifth set of experiments.

\section{Discussion}

The urinary bladder of the toad responds reproducibly and sensitively to aldosterone after prolonged incubation in steroid-free Ringer's solution. Under these circumstances exogenous glucose is required for maximal effectiveness. The results of the present study suggest that aldosterone and substrate act synergistically in regulating the rate of active transport of $\mathrm{Na}^{+}$. The increased sensitivity of the preincubated toad bladder to aldosterone presumably represents depletion of endogenous aldosterone and a concomitant decay of the chemical reactions set into play by the steroid. It has been shown previously

TABLE II

Absolute short-circuit current (scc) before and after mineralocorticoid

\begin{tabular}{|c|c|c|c|c|}
\hline $\begin{array}{l}\text { Set } \\
\text { no. }\end{array}$ & Preincubation & Steroid & $\operatorname{SCC}\left(t_{0}\right)^{*}$ & $\operatorname{sCC}\left(t_{360}\right) *$ \\
\hline \multirow{3}{*}{4} & \multirow{3}{*}{$\begin{array}{l}\text { hrs } \\
14 \frac{3}{4}\end{array}$} & & $\mu a / 2.54 \mathrm{~cm}^{2}$ & $\mu a / 2.54 \mathrm{~cm}^{2}$ \\
\hline & & 0 & $52 \pm 9$ & $37 \pm 7$ \\
\hline & & $d$-Aldosterone & $31 \pm 5$ & $67 \pm 10$ \\
\hline \multirow{2}{*}{5} & \multirow{2}{*}{13} & 0 & $60 \pm 24$ & $45 \pm 21$ \\
\hline & & $d$-Aldosterone & $31 \pm 5$ & $54 \pm 9$ \\
\hline \multirow{2}{*}{7} & \multirow{2}{*}{$14 \frac{1}{2}$} & 0 & $83 \pm 14$ & $68 \pm 15$ \\
\hline & & $d$-Aldosterone & $68 \pm 12$ & $108 \pm 17$ \\
\hline \multirow{2}{*}{$8 \dagger$} & \multirow{2}{*}{$14 \frac{1}{4}$} & Progesterone & $99 \pm 20$ & $87 \pm 20$ \\
\hline & & $d$-Aldosterone & $103 \pm 19$ & $182 \pm 27$ \\
\hline
\end{tabular}

* The values represent the mean \pm standard error of the mean.

† Only the progesterone-aldosterone subset is given from the entire eighth set of experiments. 
that responsiveness to mineralocorticoids is enhanced by adrenalectomy in man, dogs, and rats $(11,12,16)$.

We found that the combination of preincubation plus exogenous glucose provides a system in which aldosterone evokes an increase in transport work, since the rise in scc above the base line was almost as great in the face of a fivefold $\mathrm{Na}^{+}$gradient as under isomolar conditions ( $c f$. Figures 3 and 4 ). The possibility that aldosterone acts directly on the $\mathrm{Na}^{+}$pump is suggested by its effect on the flux ratio under short-circuited conditions. For the condition of a vanishingly small electrochemical gradient, Ussing and Zerahn (10) derived the relationship:

$$
E_{\mathrm{Na}}=\frac{R T}{z F} \ln \frac{J_{m s}}{J_{s m}},
$$

where $E_{\mathrm{Na}}$ denotes the electromotive force of the $\mathrm{Na}^{+}$pump. In 12 paired experiments the ratio of unidirectional fluxes of $\mathrm{Na}^{+}$was $4.4 \pm 0.6 \mathrm{six}$ hours after aldosterone compared with a ratio of $2.9 \pm 0.4$ before aldosterone. A rise in intracellular $\mathrm{Na}^{+}$concentration, however, may evoke both an increase in $E_{\mathrm{Na}}$ and in scc, so that this finding does not exclude the possibility of an action on the rate of mucosal entry of $\mathrm{Na}^{+}$into the cell. With isotopic estimates of the tissue pool of $\mathrm{Na}^{+}$as a basis, Sharp and Leaf (17) proposed that aldosterone acts at or near the mucosal face of the epithelial cells of the bladder.

Our data confirm the basic findings of Crabbé (7-9) but differ in some notable respects. In the present system the addition of aldosterone to the mucosal medium $\left(7 \times 10^{-7} \mathrm{M}\right)$ gave a similar response as addition to the serosal medium ( $c f$. Figures 3 and 6). In Crabbé's studies no effect was found with $2 \times 10^{-5} \mathrm{M}$ DOCA or $2.8 \times 10^{-5} \mathrm{M}$ cortisol or corticosterone, whereas in our studies all three were active at a concentration of $7 \times 10^{-7}$ moles per L. We also found that $9 \boldsymbol{\alpha}$-fluorocortisol and prednisolone were fully active. The 2-methyl derivatives of cortisol and $9 \alpha$-fluorocortisol were less active than cortisol or $9 \alpha$-fluorocortisol, and progesterone had no discernible activity. Imamura and Sasaki (6) found that desoxycorticosterone gluconate, cortisol, and corticosterone at a concentration of $3 \times 10^{-6}$ moles per $\mathrm{L}$ elicited equal rises in scc across the frog skin and that progesterone had little or no effect. The present findings indicate that deletion of the acetate group at the C-21 position virtually abolishes the activity and that methylation at the $\mathrm{C}-2$ site suppresses activity. These conclusions are based on studies at $7 \times 10^{-7}$ moles per L. It is likely that $7 \times 10^{-7}$ moles per $\mathrm{L}$ is close to a saturating concentration with respect to activity on $\mathrm{Na}^{+}$transport. Consequently, additional, more subtle, structure-activity relationships might appear in comparative studies at lower concentrations.

\section{Summary}

Prolonged preincubation in steroid-free media enhanced the action of exogenous $d$-aldosterone on $\mathrm{Na}^{+}$transport across the urinary bladder of the toad, Bufo marinus. ${ }^{7}$ The ability of aldosterone to augment $\mathrm{Na}^{+}$transport was dependent on an adequate supply of substrate under these conditions. Aldosterone was as effective in stimulating $\mathrm{Na}^{+}$transport against a fivefold gradient as it was in isomolar solutions. The effect of aldosterone was exerted solely on the unidirectional flux of $\mathrm{Na}^{+}$from the mucosal to the serosal phases as judged by tracer studies with $\mathrm{Na}^{22}$. At a concentration of $7 \times 10^{-7}$ moles per L, aldosterone was as active on addition to the mucosal medium as on addition to the serosal medium. Structure-activity relationships were studied at equimolar concentrations (i.e., $7 \times 10^{-7} \mathrm{M}$ ), and the order of effectiveness was found to be: $d$-aldosterone $=9 \alpha$-fluorocortisol $\geqq$ desoxycorticosterone acetate $\geqq$ cortisol $\geqq$ corticosterone $\geqq$ prednisolone $>2-\mathrm{CH}_{3}-9 \alpha$-fluorocortisol $>2-\mathrm{CH}_{3}$ cortisol $>$ progesterone $\geqq$ no steroid.

\section{Acknowledgments}

Miss Ella Highland and Mrs. Lemoyne Mueller provided valuable technical assistance throughout the course of this study.

\section{References}

1. Ross, E. J. Biological properties of aldosterone. Physiological and pathological implications. Brit. med. Bull. 1962, 18, 164.

7 We have described additional studies on the mechanism of action of aldosterone on $\mathrm{Na}^{+}$transport in a recent paper (Proc. nat. Acad. Sci. (Wash.) 1963, 50, 1169). 
2. Sawyer, W. H. The hormonal control of water and electrolyte metabolism with special reference to the amphibia. Mem. Soc. Endocrin. 1956, 5, 44.

3. Maetz, J. Le contrôle endocrinien du transport actif de sodium à travers la peau de grenouille in The Method of Isotopic Tracers Applied to the Study of Active Ion Transport. The Saclay Conference. New York, Pergamon Press, 1959, pp. 185-196.

4. McAfee, R. D., and W. Locke. Effects of certain steroids on bioelectric current of frog skin. Amer. J. Physiol. 1961, 200, 797.

5. Bishop, W. R., M. W. Mumbach, and B. T. Scheer. Interrenal control of active sodium transport across frog skin. Amer. J. Physiol. (Lond) 1961, 200, 451.

6. Imamura, A., and N. Sasaki. The effect of desoxycorticosterone-glucoside on the sodium transport in frog skin. Seitai no Kagaku 1962, 13, 73.

7. Crabbé, J. Stimulation of active sodium transport across the isolated toad bladder after injection of aldosterone to the animal. Endocrinology 1961, 69, 673.

8. Crabbé, J. Stimulation of active sodium transport by the isolated toad bladder with aldosterone in vitro. J. clin. Invest. 1961, 40, 2103.

9. Crabbé, J. The Sodium-retaining Action of Aldosterone. Presses Acad. Européennes S.C., 1963.

10. Ussing, H. H., and $\mathrm{K}$. Zerahn. Active transport of sodium as the source of electrical current in the short-circuited isolated frog skin. Acta physiol. scand. 1951, 23, 110.

11. Johnson, B. B. Bioassay of adrenal cortical steroids on the basis of electrolyte excretion by rats: effects of 11-desoxy and 11-oxy-steroids. Endocrinology 1954, 54, 196.

12. Barger, A. C., R. D. Berlin, and J. F. Tulenko. Infusion of aldosterone, 9- $\alpha$-fluorohydrocortisone and antidiuretic hormone into the renal artery of normal and adrenalectomized, unanesthetized dogs : effect of electrolyte and water excretion. Endocrinology 1958, 62, 804.

13. Maffly, R. H., and I. S. Edelman. The coupling of the short-circuit current to metabolism in the urinary biadder of the toad. J. gen. Physiol. 1963, 46, 733.

14. Heinz, E., and C. S. Patlak. Energy expenditure by active transport mechanisms. Biochim biophys. Acta (Amst.) 1960, 44, 324.

15. Frazier, H. S., E. F. Dempsey, and A. Leaf. Movement of sodium across the mucosal surface of the isolated toad bladder and its modification by vasopressin. J. gen. Physiol. 1962, 45, 529.

16. Gaunt, R., and J. J. Chart. Mineralocorticoid action of adrenocortical hormones. Handbuch der experimentellen Pharmakalogie 1962, 14, 514.

17. Sharp, G. W. G., and A. Leaf. Studies on the biological action of aldosterone in vitro (abstract). J. clin. Invest. 1963, 42, 978. 